\title{
HLA-DR2 in two sibships with insulin-dependent diabetes mellitus
}

\author{
INGEBORG DESCHAMPS, HENRI LESTRADET, MICHEL SCHMID*, \\ AND JACQUES HORS*
}

From INSERM U 83, Hôpital Hérold, and *INSERM U 93, Hôpital Saint-Louis, Paris, France.

SUMMARY We report two families selected from 124 genotyped Caucasian insulin-dependent diabetes mellitus (IDDM) families because of unusual features. In both families, all offspring are affected and four out of six bear the allele HLA-DR2 which is an uncommon phenotype among diabetic patients. Onset before the age of 1 year in all the patients of one family, association with optic atrophy in the other, and the existence of pairs of affected sibs of different HLA types in both, are infrequent findings and support the evidence of heterogeneity in IDDM.

The HLA-DR2 allele is found at a significantly lower frequency in patients with insulin-dependent diabetes mellitus than in the random population. ${ }^{12}$ This has led to the suggestion that a protective factor might be associated with this marker. ${ }^{3-5}$ We have genotyped 124 Caucasian IDDM patients, 53 of whom were included in a previous publication. ${ }^{6}$ HLA typing for A, B, C, DR, and properdin factor $B$ (Bf) alleles and haplotype assignment have been described elsewhere. ${ }^{6}$ DR2 was found in 12 index cases (gene frequency 0.05 in patients, $\mathbf{0 . 1 3}$ in 106 controls, $\chi^{2}=7.707, \mathrm{p}<0.01, \mathrm{RR}=0.35$ ) in the following allelic combinations: DR2/DR3: three cases; DR2/DR4: three cases; DR2/DR1: three cases; DR2/DR7: two cases; DR2/DR5: one case. Thus, in six cases, DR2 was combined with neither DR3 nor DR4 which could possibly be an expression of heterogeneity of IDDM. Of these, two families showing other unusual features (all offspring affected and existence of pairs of sibs of different HLA types) were selected for this report.

\section{Case reports}

FAMILY 1 (FIG 1)

The mother was born in 1945. Onset of IDDM occurred at the age of 9 months following a smallpox vaccination. Her three children, born in 1972, 1975, and 1981, are diabetic. The onset of IDDM occurred in II. 1 at the age of 7 months after a smallpox vaccination and in II. 2 (not vaccinated) at the age of 10 months following a cranial trauma. II. 3 became insulin-dependent at the age of 5 months after she

Received for publication 3 August 1982.

Accepted for publication 5 February 1983.

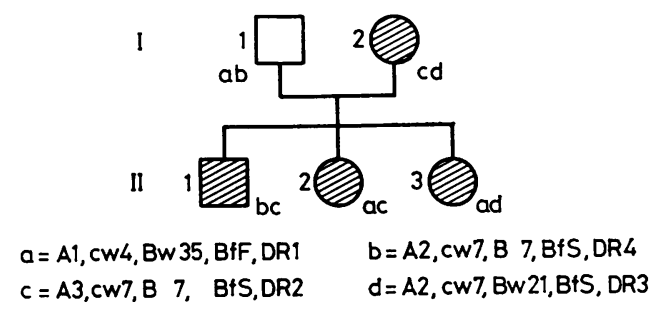

FIG 1 Pedigree of family 1 including the assignment of $H L A$ haplotypes of paternal $(a, b)$ and maternal $(c, d)$ origin. Hatched zones indicate diabetic patients (IDDM).

had shown transient hyperglycaemic episodes from birth. HLA typing showed three genotypes in the children: bc, ac, and ad. Comparisons in pairs led to the observation of two haploidentical situations (II.1, II.2 and II.2, II.3) and one non-identical (II.1, II.3). The DR2 allele is carried by the mother in combination with DR3 and by two of the children, in combination with DR1 in one and with DR4 in the other. Control of IDDM is excellent in all four patients, although there is no evidence of residual $\beta$ cell function. Cytoplasmic islet cell antibodies (ICA) were detected in the mother's serum (duration of IDDM 34 years) but not in that of the children.

\section{FAMILY 2 (FIG 2)}

There was no family history of IDDM. The three children, born in 1960,1964, and 1965, show an incomplete form of the Wolfram syndrome (IDDM, optic atrophy, diabetes insipidus, deafness ${ }^{7}$ inherited as an autosomal recessive disease with complete penetrance) with the presence of IDDM and ocular 


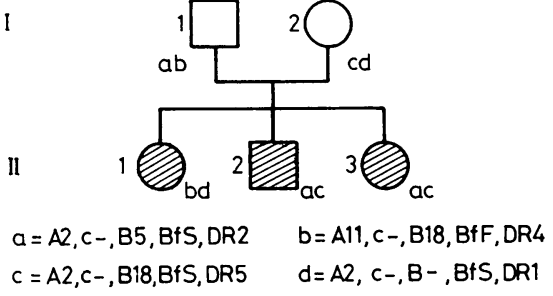

FIG 2 Pedigree of family 2 including the assignment of HLA haplotypes of paternal $(a, b)$ and maternal $(c, d)$ origin. Hatched zones indicate diabetic patients (IDDM).

symptoms in all three of them. Child II.1 developed IDDM at the age of $5 \frac{1}{2}$ years. She has had myopia, moderate optic atrophy, and daltonism since the age of 15. II.2 developed IDDM at the age of 5 years. He has had daltonism, severe optic atrophy causing near-blindness, and mild diabetes insipidus since the age of 9. II.3 developed IDDM at the age of $5 \frac{1}{2}$ years. She has had moderate optic atrophy and daltonism since the age of 8. HLA genotypes are identical in two of the sibs (II.2 and II.3), who also carry DR2 in combination with DR5, but different in the third (II.1). Control of IDDM is fair to poor in the three patients.

\section{Discussion}

Several similarities can be noted between the two reported IDDM families. (1) All sibs are affected and there is one pair of affected sibs of different HLA types in each family. (2) HLA-DR2 is present in five out of seven patients. (3) Early onset of IDDM occurred at similar ages in both sibships. The clinical features, although different in both families, are similar within each sibship.

In the case of family 1 , a hypothesis can be put forward for unusual immunological mechanisms which could explain the extremely early onset of the disease in all three sibs: the mother developed autoanti-islet cell antibodies which were still present 34 years after onset of the disease. Although relatively frequent at the time of diagnosis, these antibodies decline in frequency in time. They belong mostly to the IgG class. In this case, it can be postulated that in passing through the placental barrier during pregnancy, they could have triggered off fetal $\beta$ cell lesions by initiating autoimmune antibody-dependent cell-mediated cytotoxicity in her three children, resulting in the unusually early onset of IDDM.

In family 2 , the presence of an incomplete form of the Wolfram syndrome in the three sibs, of whom one is a different HLA type from the other two, supports the view that this syndrome is not HLA linked and that it could be a disorder distinct from classical type I diabetes. This has already been suggested in one family. ${ }^{8}$ However, as these patients were only typed for HLA-A and -B, a recombination at the DR locus of the sib with a different HLA type could not be excluded.

In both families presented, the HLA-DR2 allele did not contribute to a more favourable course of the disease, since similar clinical patterns were observed whether or not patients carried DR2.

Our observation correlates with that of Weitkamp ${ }^{9}$ who found less haplotype sharing in families with three or four affected sibs than in those with two affected sibs. This raises the question of more than one susceptibility locus, ${ }^{1011}$ which could be more apparent in families with several affected subjects, and provides evidence suggesting genetic heterogeneity of juvenile onset IDDM.

We should like to thank patients and relatives and the AJD for their kind cooperation. This work was supported by a grant from the Caisse Nationale d'Assurance Maladie and INSERM ATP 78-89.

\section{References}

1 Svejgaard A, Platz P, Ryder LP. Insulin-dependent diabetes mellitus. Joint report of the 8 th International Histocompatibility Workshop. In: Terasaki P, ed. Histocompatibility testing. Los Angeles: UCLA Tissue Typing Laboratory, 1980.

2 Platz P, Jakobsen DK, Morling N, et al. HLA-D and DR antigens in genetic analysis of insulin-dependent diabetes mellitus. Diabetologia $1981 ; 21: 108-15$.

3 Ilonen J, Herva E, Tiilikainen A, et al. HLA-Dw2 as a marker of resistance against juvenile diabetes mellitus. Tissue Antigens 1978;11:144-6.

4 Cudworth AG, Festenstein H. HLA genetic heterogeneity in diabetes mellitus. Med Bull 1978;34:285-9.

5 Ludwig H, Schernthaner G, Mayr WR. The importance of HLA genes to susceptibility in the development of juvenile diabetes mellitus. Diabete Metab 1977;3:43-8.

6 Deschamps I, Lestradet $\mathrm{H}$, Bonaïti $\mathrm{C}$, et al. HLA genotype studies in juvenile insulin-dependent diabetes. Diabetologia 1980;19:189-93.

7 Cremers CWRJ, Wijdeveld PGAB, Pinckers AJLG. Juvenile diabetes mellitus, optic atrophy, hearing loss, diabetes insipidus, atonia of the urinary tract and bladder and other abnormalities (Wolfram syndrome). Acta Paediatr Scand (Suppl) 1977;264:1-16.

${ }^{8}$ Stanley CA, Spielman RS, Zmijewski CM, Baker L. Wolfram syndrome not HLA linked. $N$ Engl J Med 1979; 301:1398-9.

9 Weitkamp LR. HLA and disease: predictions for HLAhaplotype sharing in families. Am J Hum Genet 1981 ;33: 776-84.

10 Suarez BK, Van Eerdewegh P. Insulin-dependent diabetes mellitus. Is there strong evidence for a non-HLA linked gene? Diabetologia $1981 ; 20: 524-9$.

11 Clerget-Darpoux F, Bonaïti-Pellie C, Hors J, Deschamps I, Feingold N. Application of the lod-score method to detection of linkage between HLA and juvenile insulindependent diabetes. Clin Genet 1980;18:51-7.

Correspondence and requests for reprints to $\mathrm{Dr}$ I Deschamps, INSERM U 83, Hôpital Hérold, 7 Place Rhin et Danube, 75019 Paris, France. 